\title{
STUDYING INTERNATIONAL COMPETITIVENESS IN PHARMACEUTICAL SECTOR IN SELECTED DEVELOPED COUNTRIES
}

\author{
SEYEDE ZEINAB MOUSAVI ${ }^{1}$, SAEED RASEKHII ${ }^{1}$, MINA GOLESTANI ${ }^{2 *}$, ALI IMANI ${ }^{3}$ \\ ${ }^{1}$ Department of Economics, Faculty of Economics and Administrative Sciences, University of Mazandaran, Babolsar, Iran. ${ }^{2}$ Department ${ }^{\circ}$ \\ Road Traffic Injuries Research Center, Tabriz University of Medical Sciences, Tabriz, Iran. ${ }^{3}$ Department of Health Economics, Health \\ Services Management Research Center, Faculty of Management and Medical Informatics, Tabriz University of Medical Sciences, Tabriz, \\ Iran. Email: mgolestani8958@gmail.com
}

Received: 10 November 2017, Revised and Accepted: 06 December 2017

\begin{abstract}
Objectives: Competitiveness is the ability of countries in increasing market share, profits, value added, and staying at the scene of fair and international competition for a long period of time. This is realized through market authority and establishing activities based on comparative and competitive advantages. On the other hand, the research-based pharmaceutical industry makes a major contribution to the prosperity of the world economy. It is a robust sector that has been one of the pillars of industrialized economies and is increasingly recognized as an important sector in the developing world as well. Furthermore, global sales of pharmaceutical products represent the international spread of medical technology that comes as the result of highly intensive R and D efforts in the exporting countries (International Federation of Pharmaceutical Manufacturers and Associations, 2012). The present study aimed to analyze and investigate the international competitiveness of pharmaceutical sector in selected developed countries using traditional and new indices of competitiveness.
\end{abstract}

Methods: In this study, revealed comparative advantage index and also static and dynamic intra-industry trade (IIT) indices were used in the period 2000-2012.

Results: The results indicated the growing competitiveness in most of the selected countries. Furthermore, the findings suggested that countries with higher levels of international trading of pharmaceutical goods have a higher potential of competitiveness based on IIT and comparative advantage indices.

Conclusions: For increase in international competitiveness in pharmaceutical industry, selected developed countries pay attention to both comparative and competitive advantages.

Keywords: Competitiveness, Revealed comparative advantage, Intra-industry trade, Pharmaceutical industry, Selected countries.

(C) 2018 The Authors. Published by Innovare Academic Sciences Pvt Ltd. This is an open access article under the CC BY license (http://creativecommons. org/licenses/by/4. 0/) DOI: http://dx.doi.org/10.22159/ajpcr.2018.v11i3.21554

\section{INTRODUCTION}

The most basic infrastructure required for entering international realm is creating a competitive environment. In today's complicated and rapidly changing world, one of the major concerns of countries is to increase their own power of competitiveness and consequently increase the welfare and comfort of their citizens. Creating a competitive environment in a country leads to the growth of advantaged sectors through expansion of their markets from the national to international levels [1]. In fact, countries are always struggling with foreign trade affaires that are divided to traditional and new ones. Meanwhile, only those countries can be successful in solving their exports and imports problems that plan a specific program based on their own long-term economic, social, and cultural objectives. One significant issue in this process is countries' awareness of their own comparative advantages in production and exports of goods [2]. Comparative advantage is among main topics in traditional theories of international trade. If comparative advantages are identified and realized properly, the process of development, whether in the form of economic development strategy, replacement of imports, and supporting export, or a combination of them can be rapid and sustainable. Therefore, identifying comparative advantages is a reliable guidance and an attractive factor for internal and external investments [3].

However, since comparative advantage is a dynamic concept rather than a static and permanent one and it is possible to convert comparative advantages into competitive advantages by reducing production costs and promoting the quality of manufactured goods, countries have to create competitive advantages to improve competitiveness in the international arena. Empirical findings suggest that, in addition to invention and innovation, cost-saving operations, change in the initial inventory of resources due to finding new resources, efficiency in production, and expertise and skills can change the comparative advantages of countries. In this regard, the concept of intra-industry trade (IIT) gains a specific position because more differentiation among goods itself is related to the concept of IIT.

In fact, traditional theories basically relate the reason of trades in countries to their cultural differences (in terms of technology, inventory of factors, and preferences). However, a significant share of international trade is done between developed countries with somehow similar structures. It can be said that similarity of the structures leads to a different style of trading called IIT. In fact, IIT happens when a country simultaneously imports and exports identical goods. In this kind of trade, a country can be the importer of the same good which exports it [4].

Medicine plays a crucial role in the proper performance of health services. Many of medical and preventive measures depend on medicines, and patients consider its availability as the quality of health services [5]. Today, drug trade is one of the most profitable kinds of trade in the world. Big pharmaceutical companies try to gain more money through inventing new drugs. Pharmaceutical industry is both a sensitive and 
profitable stream, in a way that average per capita consumption of drugs in the world is $94 \%$ [6]. Hence, studying competitiveness of pharmaceutical industry in developed countries to understand their status in the world and analyzing their success in this field seems highly important. The present study aims to find the position of the global of pharmaceutical industry in selected developed countries through analyzing and investigating the international competitiveness using traditional and new indices of international trade including comparative advantage indices and static and dynamic indices of IIT.

\section{METHODS}

In the present study, to assess the competitiveness of developed countries in pharmaceutical industry, comparative and competitive advantages were analyzed through mixing traditional and new indices at two static and dynamic levels.

\section{Methods of measuring traditional indices of comparative} advantage

In recent years, much effort has been made to measure comparative advantage. In this part, indices of determining comparative advantage in functional method that is based on prices after the process of trading are presented.

\section{Balasa's developed index}

In 1991, Thomas Walrus in his article talked about limitations of Balassa's indices and stated that Balassa's index can be expanded for reflecting the world comparative advantage through considering all countries and commercial goods. Hence, this index was revised and presented as follows:

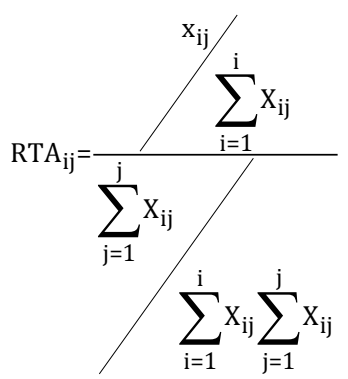

Where i denotes the studied good or industry, and j represents the studied country. If RCA>1, it indicates the existence of revealed comparative advantage, and if $0<\mathrm{RCA}<1$, it shows lack of comparative advantage in exporting the given good. If $R C A=1$, then it means that country $j$ has no superiority or inferiority over other countries in exporting a given good. Progressive growth of this index over time shows improvement in the competitive position of a good in the world or in a specific region [7].

\section{Relative export advantage index}

Walrus (1987), with the aim of improving Balasa's index and criticizing double counting of exports in calculation of this index, introduced RXA as follows:

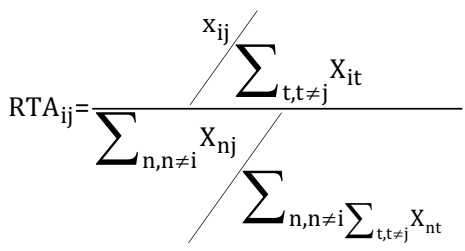

Where $\mathrm{X}, \mathrm{i}, \mathrm{j}, \mathrm{t}$, and $\mathrm{n}$, respectively, represent exports, the studied product, the studied country, other countries, and other exported goods [8]. Interpretation of this index is similar to RCA.

\section{Relative trade advantage (RTA)}

Walrus (1989), considering a lack of including imports in the calculation of RCA and RXA, defined RTA. This index shows the difference between comparative advantages of imports and exports [8].
$\mathrm{RTA}_{\mathrm{ij}}=\mathrm{RXA}_{\mathrm{ij}}=\mathrm{RMA}_{\mathrm{ij}}$

In equation $3, \mathrm{RXA}_{\mathrm{i}}$ denotes comparative advantage of exports in country $\mathrm{j}$, and $\mathrm{RMA}_{\mathrm{ij}}$ represents the comparative advantage of imports in country i. Values more than zero indicate the comparative existence of advantage, and values $<0$ show a lack of comparative advantage.

\section{Index of revealed symmetric comparative advantage}

Asymmetry in revealed comparative advantage is considered as one of its weaknesses. To solve this problem, Brassily et al., in 2000, presented a symmetric or normal form of this index:

$$
\operatorname{RSCA}_{i j}=\frac{\operatorname{RCA}_{i j}-1}{\operatorname{RCA}_{i j}+1}
$$

Revealed symmetry comparative advantage index ranges between -1 and +1 . Positive scores show the existence of comparative advantage and negative scores represent a lack of comparative advantage. Due to limited range of this index, it can be said that more proximity of SRCA to +1 leads to more comparative advantage. On the other hand, more proximity to -1 suggests lack of expected advantage [9].

\section{Indices of measuring IIT}

To complete the results of calculation of comparative advantage indices and assess competitive advantage of pharmaceutical goods, the new indices of IIT were applied. IIT indices are divided into static and dynamic indices. Based on theoretical foundations, weighted index of Grubel and Lloyd and also Fontagne and Freudenberg are among static indices, and Brulhart and $\mathrm{AE}$ indices are in the area of dynamic ones [10]. They will be studied in detail in the following sections.

\section{Grubel and Lloyd index}

In 1975, Grubel and Lloyd presented an index for measuring IIT. They criticized Balassa's index for not being weighted and introduced a weighted index to measure IIT for all industries. The weighted index of Grubel and Lloyd for measuring IIT of country $\mathrm{j}$ is as follows:

$\mathrm{GL}_{\mathrm{j}}=\sum_{\mathrm{j}=1}^{n} \mathrm{~W}_{\mathrm{j}} \mathrm{GL}_{\mathrm{j}}=\frac{\sum_{\mathrm{j}}\left(\mathrm{X}_{\mathrm{jk}}+\mathrm{M}_{\mathrm{jk}}\right)-\sum_{\mathrm{j}}\left|\mathrm{X}_{\mathrm{jk}}-\mathrm{M}_{\mathrm{jk}}\right|}{\sum_{\mathrm{j}}\left(\mathrm{X}_{\mathrm{jk}}+\mathrm{M}_{\mathrm{jk}}\right)}$

Weight of this equation is measured as follows:

$\mathrm{W}_{\mathrm{j}}=\frac{\mathrm{X}_{\mathrm{jk}}+\mathrm{M}_{\mathrm{jk}}}{\sum_{j}\left(\mathrm{X}_{\mathrm{jk}}+\mathrm{M}_{\mathrm{jk}}\right)}$

In which $(\mathrm{Mj}) \mathrm{Xj}$ is the import or export of industry or country to or from other parts of the world. This index ranges between 0 and 1 . If the amount of GL index is equal to 1, IIT would be pure, and if this amount is zero, the entire trade will be IIT.

\section{Index of different kinds of trade}

Fontagne and Freudenberg (1997) proposed a new approach for measuring IIT and divided it into vertical IIT and horizontal IIT. This index is measured in two stages. In the first stage, based on overlapping rule, reciprocal (exports and imports) trade is divided into one-way or two-way trade. On the basis of this criterion, if the value of minimum flow is at least $10 \%$ of maximum flow, then trade will be two-way that is as follows:

$$
\frac{\min \left(\mathrm{X}_{\mathrm{kk} / \mathrm{it}}, \mathrm{M}_{\mathrm{kk} / \mathrm{it}}\right)}{\max \left(\mathrm{X}_{\mathrm{kk} / \mathrm{it}}, \mathrm{M}_{\mathrm{kk} / \mathrm{it}}\right)}>10 \%
$$

If the value of minimum stream is lower than this, it would be considered structural. In this case, gross trade flow would be one-way. 
In the second stage, the following equation is established to divide IIT to its different kinds.

$$
\frac{1}{1+\alpha} \leq \frac{\mathbf{U V}_{\mathrm{k}}^{\mathrm{x}} \leq 1+\alpha}{\mathbf{U V}_{\mathrm{k}}^{\mathrm{m}}}
$$

Where $\bigcup_{\mathrm{k}}^{\mathrm{x}}\left(\bigcup_{\mathrm{k}}^{\mathrm{m}}\right)$ denotes the value of exports and $\alpha$ represents the parameter of similarity $(0.15)$. If the ratio of unit value ranges between 0.87 and 1.15 , products are horizontally differentiated; otherwise, they would be vertically differentiated. Finally, the share of every kinds of trade from the whole entity will be measured.

\section{Comparative indices of Brulhart}

In 1994, Brulhart introduced his set of dynamic indices. Index of $B^{B}$ is assessed as follows:

$$
\mathrm{AE}=\frac{\Delta \mathrm{X}-\Delta \mathrm{M}}{2 \max (|\Delta \mathrm{X}|,|\Delta \mathrm{M}|}
$$

This index, similar to GL index, rests between 0 and 1. Zero represents that marginal trade in a specific industry is in IIT form [11]. It is measured for the entire industry as follows:

$$
\mathrm{B}_{\text {tot }}^{\mathrm{A}}=\sum_{\mathrm{i}}^{\mathrm{k}} \mathrm{W}_{\mathrm{i}} \mathrm{B}_{\mathrm{i}}^{\mathrm{A}}
$$

In which $\mathrm{B}_{\text {tot }}^{\mathrm{A}}$ represents the weight mean of Brulhart index for all industries or all subparts of one industry [11].

Index $\mathrm{B}^{\mathrm{B}}$ is calculated as follows:

$$
\begin{aligned}
& \mathrm{B}^{\mathrm{B}}=\frac{|\Delta \mathrm{X}-\Delta \mathrm{M}|}{|\Delta \mathrm{X}|+|\Delta \mathrm{M}|} \\
& \left|\mathrm{B}^{\mathrm{B}}\right|=1-\mathrm{BA}
\end{aligned}
$$

$\mathrm{B}^{\mathrm{B}}$ rests between -1 and 1 . This index contains two groups of information: First, more proximity of $\mathrm{B}^{\mathrm{B}}$ to zero results in higher MIIT. If $\mathrm{B}^{\mathrm{B}}$ is zero, marginal trade would be in IIT form. If this index ranges between -1 and 1 , marginal trade would be totally IIT. Second, if $\mathrm{B}^{\mathrm{B}}$ is more than zero, changes in exports would be more than imports and vice versa. Therefore, $\mathrm{B}^{\mathrm{B}}$ is directly related to unit performance. This index has a major problem that is no possibility of reaching a meaningful sum for industries [11].

\section{Index of Azhar and Elliot}

Another measure was proposed by Azhar and Elliot (2001) which is as follows:

$$
\mathrm{AE}=\frac{\Delta \mathrm{X}-\Delta \mathrm{M}}{2 \max (|\Delta \mathrm{X}|,|\Delta \mathrm{M}|}
$$

This index rests between -1 and 1 . If the trade balance is destroyed in the given period, this index will be negative and vice versa. In the case of different marks for $\Delta \mathrm{X}$ and $\Delta \mathrm{M}$, there would be no MIIT. In this case, $B^{B}$ rests between -1 and 1 . $A E$ index shows this range with more details because it discriminates among relative measures of changes in net trade. Therefore, the range of information in $\mathrm{B}^{\mathrm{B}}$ is a subset of $\mathrm{AE}$ index [11].

\section{RESULTS}

\section{Analyze and investigate of comparative advantage indices} Analysis of revealed comparative advantage in selected developed countries

The studied countries were chosen based on the measurement of the mean of world traded pharmaceutical goods. In this regard, the selected countries included the European Union, Germany, USA, Belgium, Switzerland, United Kingdom, France, Italy, Ireland, Netherlands, Spain, Japan, Canada, Sweden, Austria, Australia, Denmark, Singapore, Greece, Hungry, Czech Republic, South Korea, Finland, Portugal, Hong Kong, Slovenia, Norway, Slovakia, New Zealand,l and Luxemburg. Table 1 summarizes the results of comparative advantage indices in developed countries during 2000-2012 (including countries with higher and lower levels of pharmaceutical goods trade compared to other selected countries).

According to the results, among 30 countries, only 13 one had comparative advantage. Among them, advantages of the European Union, Italy, Sweden, Denmark, and Greece faced a decrease during the study. Based on these results, Switzerland, Ireland, Slovenia, Denmark, and United Kingdom had the highest revealed comparative advantage among other countries with mean RCA of $6.52,6.15,2.59,2.23$, and 2.17 , respectively. In this regard, according to the report of the Organization of Economi Cooperation and Development (OECD), Switzerland and Ireland were among the main pharmaceutical markets in 2011. It can be claimed that Switzerland has topped other countries of the world in production and exports of pharmaceutical products with high quality. Based on reports of the Institution of Commercial Researches and Studies, in 2013, a pharmaceutical company in Switzerland, named "Novartis", was selected by Forbes as the most magnificent company in the field of pharmaceutical in the world for the $3^{\text {rd }}$ consecutive year. This company, also, received the honor of most creative pharmaceutical company for the $3^{\text {rd }}$ consecutive year. Novartis is a multinational company consisted of different firms which are active in the field of research and development, production, and marketing of medical care products. In 2005, Novartis bought German company of Hexal and US Company of Eon Labs, and by this, introduced itself as one of the biggest company producing generic medicines. Reports regarding pharmaceutical industry in Ireland show that this country sits on the top of net drug exporters and is the seventh big exporter of the world. Ireland is the country where 120 best-selling international pharmaceutical companies. In addition, among 10 top global drug agencies, 9 one are in Ireland. Pharmaceutical industry in Ireland is so vast and advanced that accounts for half of all exports of this country.

Moreover,SouthKorea, Belgium, and HongKonghavethehighestamount of RCA in the given period. More considerations show that Netherlands and Hungry, despite the lack of comparative advantage in the study period, had a comparative advantage in some years. Furthermore, RCA of Hungry was promoted as a result of some fluctuations. The results obtained from the mean of RCA index indicate the fact that countries like USA, Belgium, Netherlands, Japan, and Canada do not have relative advantage. Among them, Netherlands and USA, in spite of not having relative advantage, experienced having such an advantage in 2009, 2000, 2004-2007, and 2011-2012, respectively. Reports show that they are among top countries in the arena of pharmaceutical trade. According to the report of OECD, the USA is among both the biggest exporters and importers of medicines. Furthermore, based on previous studies, USA is the world's largest drug consumer. Other industrial countries like Japan, France, Belgium, Ireland, and Germany are in the other ranks of drug consumption. Therefore, it can be concluded that although relative advantage is a prerequisite for survival in the realm of global competition and reaching top ranks, it is not the only required condition, and countries are able to promote their own capacity in manufacturing through creating factors of competitive advantage, which results in more competitiveness power. It should be 
mentioned that the right of registering new invented drugs can be a main factor in attracting investments in most of developed countries. For example, a powerful patent system, along with a market without price control, led to a huge flow of investment in pharmaceutical industry, and advertisement has a direct effect on raising the demand and prescription of all the medicines [12].

Based on the results, the trend of RCA index in most of developed countries, as shown in Fig. 1, has rather little fluctuation. This shows coherent and operational policies and plans of developed countries in expanding manufacturing and exports of pharmaceutical products and promoting their international competitiveness.

Analysis of revealed symmetric comparative advantage in selected developed countries

According to the results shown in Table 1, RSCA index results fully supports the results of RCA index. Accordingly, only EU region, Germany, Switzerland, United Kingdom, France, Italy, Ireland, Spain, Sweden, Austria, Denmark, and Slovenia have a comparative advantage in pharmaceutical industry, and other selected developed countries lack such an advantage. Interpreting these results points to rather high volume of global trade of pharmaceutical goods in these countries among which Switzerland, Italy, and Ireland are at the top ten ones. However, Denmark, and especially, Slovenia are in lower ranks of medicine trade. Based on the results of revealed symmetric comparative advantage index, Italy, Sweden, Denmark, Greece, and EU region faced a decrease in their comparative advantage. Countries like USA, Belgium, Canada, Singapore, Hungry, South Korea, Finland, and Luxemburg, in spite of lacking comparative advantage during the study period, showed an increasing trend. Their RSCA index promoted at the end of this period. Trend of this index indicates that in most of selected developed countries, it had some fluctuations, but these fluctuations were less than those in RCA index. This suggests coherent and purposeful policies of pharmaceutical industry in developed countries.
Analysis of relative export advantage index in selected developed countries

Based on Table 1 and the results obtained from mean RXA index, it can be claimed that findings are consistent with two previous indices and approve them. The only difference is that, along with 13 common countries, Belgium also possesses relative advantage in the given period. The process of RXA index for Belgium was incremental. Due to big volume pharmaceutical trade in Belgium, this conclusion seems to be rational. Moreover, the trend of these indices in selected countries was sometimes different. Fig. 2 shows RXA trend. In this regard, Belgium, Switzerland, Ireland, Slovenia, and United Kingdom have the highest relative advantage. The results suggest that RXA index for pharmaceutical goods in Germany, USA, Belgium, Switzerland, United Kingdom, France, Ireland, Spain, Canada, Austria, Singapore, Hungry, South Korea, Finland, Slovenia, and Luxemburg had a progressive trend, but in Italy, Netherlands, Japan, Sweden, Australia, Denmark, Greece, Czech Republic, Portugal, Hong Kong, Norway, Slovakia, New Zealand, and EU region, this index faced a relatively downward trend. Furthermore, RXA index in pharmaceutical industry in all countries experienced some fluctuations.

\section{Analysis of RTA in selected developed countries}

According to the findings obtained from running RTA, the results were somehow different from previous ones. This index shows that many of selected countries lack comparative advantage, and only Germany, USA, Switzerland, United Kingdom, France, Ireland, Sweden, Austria, Denmark, Singapore, and Slovenia enjoy such an advantage. Among them, Ireland, Switzerland, Slovenia, EU, and the United Kingdom have the highest RTA. Moreover, countries of EU, Germany, USA, Switzerland, and Denmark had a decreasing process and faced less advantage at the end of this period. Belgium, Italy, Netherlands, and Spain had advantages in some time. At the end of this period, RTA in Italy was reduced, but it promoted in Belgium, Netherlands, and Spain. In other countries lacking comparative advantage, RTA finally increased,

Table 1: Mean of competitiveness indices of pharmaceutical industry in selected developed countries during the period 2000-2012

\begin{tabular}{|c|c|c|c|c|c|c|}
\hline Rank in pharmaceutical trade & Country & RCA & RSCA & RXA & RMA & RTA \\
\hline 1 & EU-27 & 1.93 & 0.32 & 2.25 & 0.92 & 1.33 \\
\hline 3 & USA & 0.869 & -0.072 & 0.856 & 0.782 & 0.074 \\
\hline 5 & Switzerland & 6.52 & 0.731 & 8.39 & 3.53 & 4.86 \\
\hline 7 & France & 1.88 & 0.304 & 1.99 & 1.36 & 0.629 \\
\hline 9 & Ireland & 6.15 & 0.705 & 7.81 & 1.53 & 6.29 \\
\hline 24 & Portugal & 0.358 & -0.447 & 0.378 & 1.18 & -0.802 \\
\hline 25 & China, Hong Kong SAR & 0.109 & -0.804 & 0.104 & 0.13 & -0.026 \\
\hline 27 & Norway & 0.165 & -0.817 & 0.16 & 0.826 & -0.686 \\
\hline 30 & Luxembourg & 0.163 & -0.721 & 0.159 & 0.629 & -0.471 \\
\hline
\end{tabular}

Calculations of research

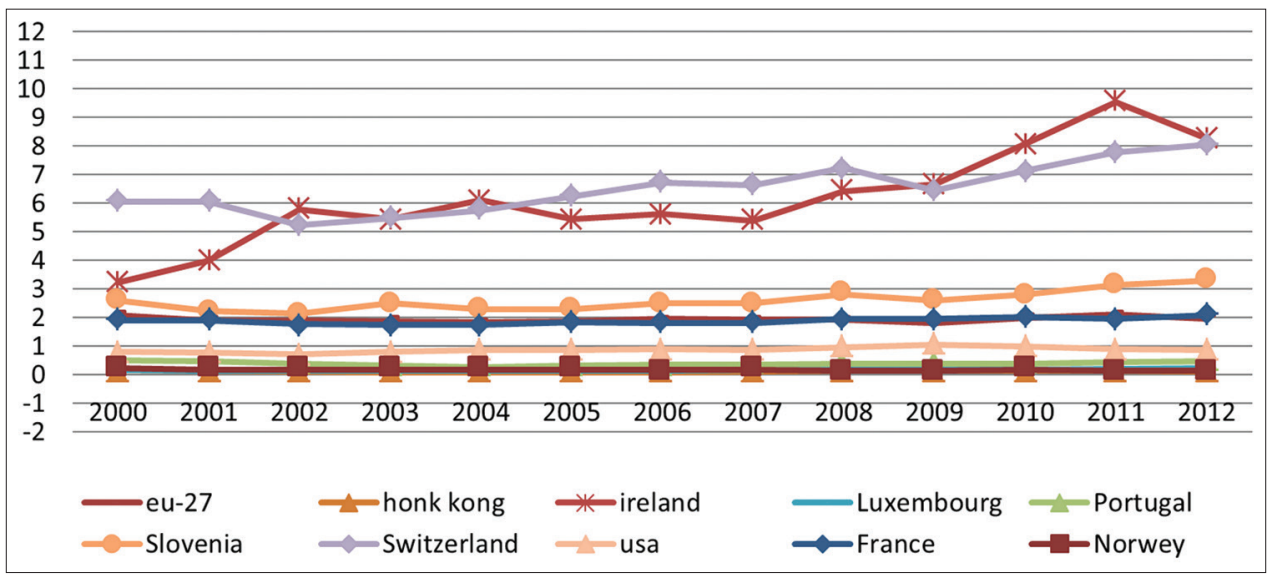

Fig. 1: Trend of revealed comparative advantage of pharmaceutical industry in selected developed countries during the period $2000-2012$ 
showing the decreasing trend of lacking advantage of them during this period. Fig. 3 depicts the trend of this index.

Therefore, all comparative advantage indices, roughly through correlation between each other, show lack of export comparative advantage during 2000-2012 in most of developed countries. However, there are some differences between countries. Among developed countries, Switzerland, Ireland, and Slovenia, based on all indices of export comparative advantage, have the highest comparative advantage in pharmaceutical goods during 2000-2012. The trend of these indices in developed countries is less fluctuated than developing countries.

\section{Measurement and analysis of IIT indices in selected developed} countries

Analysis of weighted index of Grubel and Lloyd

Based on theoretical foundations of IIT, trade of homogenized goods occurs in developed countries with similar production factors. Concerning various findings of different studies, many of researches after Grubel and Lloyd showed that the structure of trade in very advanced

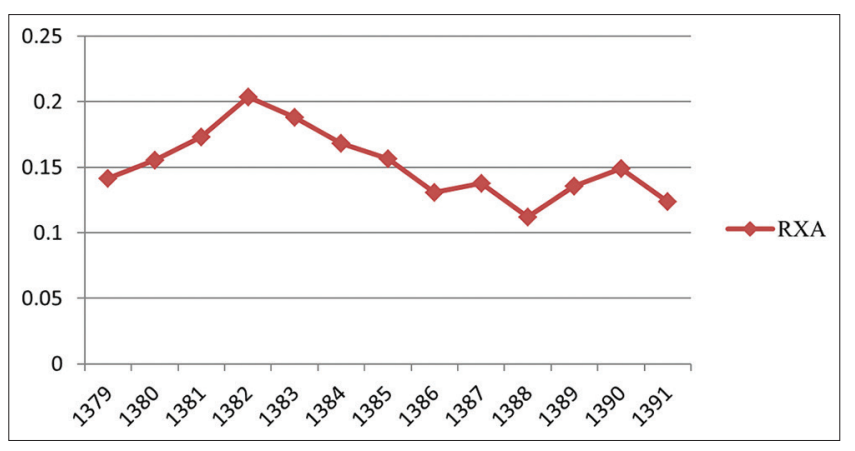

Fig. 2: RXA Index trend

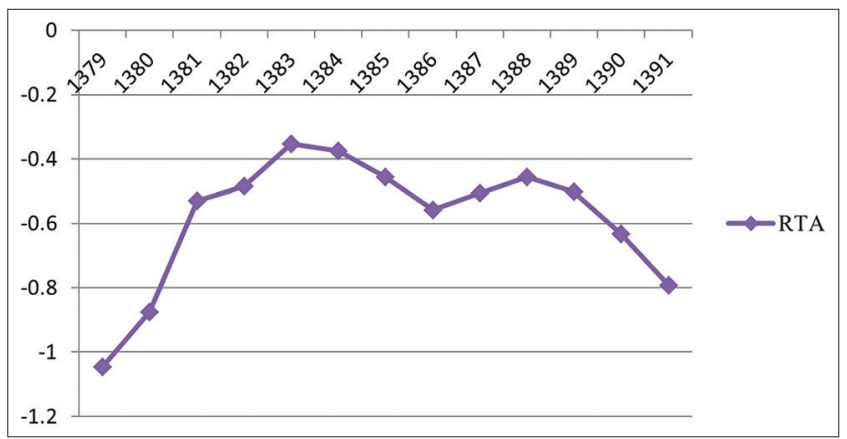

Fig. 3: RTA index trend economies would be so specialized. Thus, it seems that industrialized countries have higher levels of IIT compared to developing countries. The results about IIT in selected countries are consistent with the findings of previous empirical and theoretical researches and clarify the high volume of IIT in developed countries. In this regard, Netherlands, Belgium, Italy, Spain, Hong Kong, France, and the United Kingdom had the highest IIT (more than 70\%), while Ireland, Luxemburg, New Zealand, Norway, Greece, Slovakia, and Portugal showed the lowest volume of IIT (lower than 35\%). Therefore, the volume of exports in successful countries led to an increase in IIT. Hence, higher levels of IIT reflect more capability of a variable commercial environment. Extensive study of countries whose main share of trade relates to IIT showed that they have gradually promoted their IIT at the end of the given period. The trend of GL index in these countries has been shown in Fig. 4. Large variations in IIT contribute to more flexibility of countries to adapt to global competition. Moreover, it should be noted that among selected developed countries, Belgium, USA, and Netherlands, despite having comparative advantage in pharmaceutical sector, possess a high level of IIT in medicines. This is logical and can be said that they have not relied only on comparative advantages and used some factors to create comparative advantages in pharmaceutical industry, including saving capitals, distinguishing products in deficit markets, size of market, attracting foreign investments, and utilizing state-ofthe-art technologies. Countries like Hungry and Hong Kong, in spite of having lower volume of trade in pharmaceutical goods compared to other developed countries, are of high IIT in medicine trade. This manifests the attempts of their officials to gain competitive advantage in the sphere of international trade. However, Ireland, Slovenia, and Greece experienced a reverse situation, in a way that, despite having a high volume of pharmaceutical trade, they had low IIT. Then, it can be claimed that pharmaceutical goods trade in these three countries was mainly based on common theories of trade, with the domination of inter-industry trade.

Furthermore, the results indicate that among countries with small share in IIT over the study period, Greece, Czech Republic, Portugal, Norway, Slovakia, New Zealand, and Luxemburg faced an increase in IIT for pharmaceutical goods. This suggests a change in the structure of international trade from inter-industry to intra-industry. In other words, it can be stated that IIT in these countries was empowered through expansion of information and telecommunication technology, strengthening open-door policies, focusing on similar cultures in different countries, and increasing the extent to which the economy of countries is open.

In contrast, Ireland, Japan, South Korea, and Slovenia had a decreasing slope and faced lower levels of IIT. This shows that much of medicine trade in these countries was in the form of inter-industry which has gradually gained more attention.

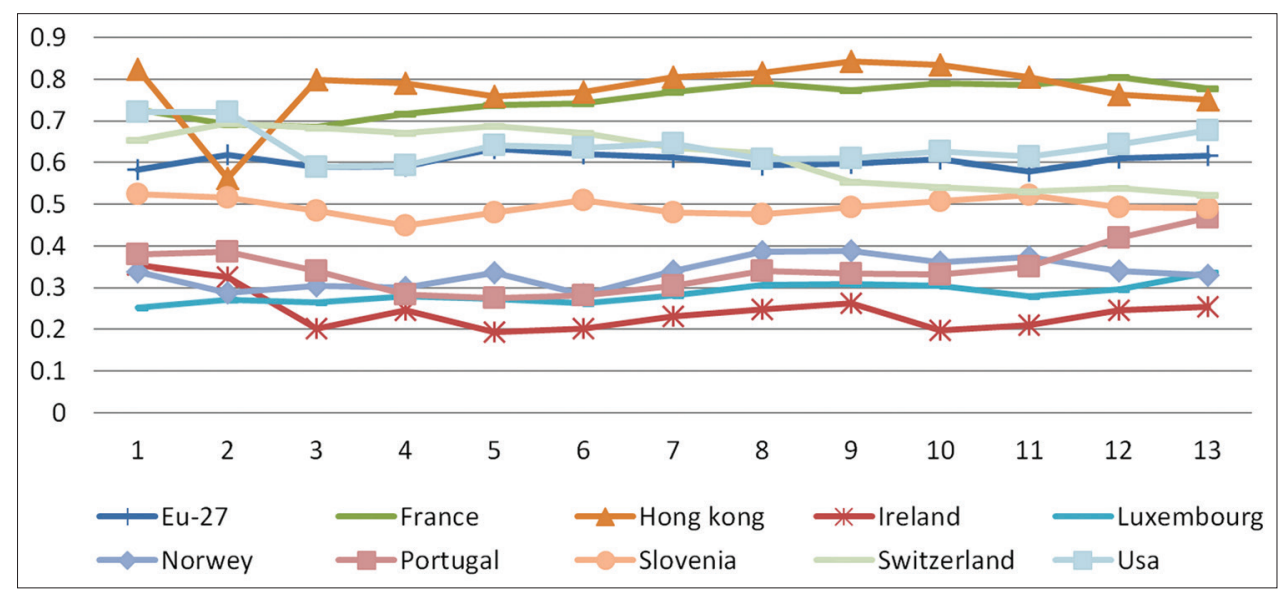

Fig. 4: The trend of IIT index of pharmaceutical goods in selected developed countries during 2000-2012 
Analysis of different methods of trade (Fontagne and Freudenberg) In this part, due to lack of complete data regarding weights of some pharmaceutical goods in some countries, distinguishing vertical and horizontal IIT was done only for the USA, Switzerland, United Kingdom, France, Italy, Ireland, Spain, Japan, Denmark, Greece, Czech Republic, South Korea, Portugal, Norway, and Luxemburg.

Based on these measurements and mean of FF index for developed countries (Tables 2 and 3), two-way trade was prominent in foreign transactions of pharmaceutical goods. Much of this two-way trade was allocated to vertical intra industry trade. This, on one hand, shows that the high ratio of trade in developed countries is IIT and, on the other hand, suggests that competitive pressure on pharmaceutical goods is so small. This means that differences in pharmaceutical sector in developed countries result from qualitative differences rather than facial ones.

Among these countries, only Ireland had a one-way trade in pharmaceutical sector which has promoted at the end of the given period. This suggests the fact that pharmaceutical sector in Ireland follows IIT process and benefits from comparative advantages. In addition, among developed countries, the horizontal IIT possessed a high proportion of trade only in France. In Spain, Japan, Greece, Czech Republic, and Luxemburg, horizontal IIT was prominent in some years. In most of countries, horizontal IIT showed a decrease at the end of the given time and vertical IIT bloomed. Only Czech Republic, Greece, Portugal, and Luxemburg experienced an increase in MIIT at the end of the given time.

Moreover, measuring identical values indicate that a great part of IIT in pharmaceutical sector in some countries belongs to goods with low quality, which was notstable, and in someyears, it was in reverse position and goods with high quality were traded. Among them, Switzerland, United Kingdom, France, Japan, Denmark, Ireland, and Luxemburg have traded goods with high quality in most of the time. This means that they exported expensive and high-quality pharmaceutical goods.

\section{Analysis of comparative indices of Brulhart $\left(B^{A}\right.$ and $\left.B^{B}\right)$}

The results of Brulhart index $\left(B^{B}\right)$ for pharmaceutical groups in selected countries are shown in Table 4 According to the results, all developed countries had a progressive process in IIT in the given period. In other words, reviewing $\mathrm{B}^{\mathrm{B}}$ index of all countries shows that MIIT of pharmaceutical goods generally had a partially appropriate growth. This indicates the importance of new methods of trade and development of trading identical goods in pharmaceutical sector in these countries. Germany, USA, Belgium, United Kingdom, and France had the highest growth. This is not surprising because they have a huge amount of trade in pharmaceutical goods. Other countries, with rather high volume of medicine trade, experienced a good growth in different periods. Among them, Hong Kong, although having a small volume of trade, experienced a dramatic promotion in MIIT for pharmaceutical goods. This suggests its great potential in gaining competitive advantage in pharmaceutical sector. The results indicate that Greece, Portugal, Luxemburg, Japan, Finland, and Slovakia had the lowest MIIT in the specified period. It should be noted that most countries, along with having a variable trend, finally were of good MIIT. On the other hand, in most developed countries, a smaller amount of pharmaceutical goods trade was interindustrial. Therefore, the results indicate a change in the structure of pharmaceutical goods from extra to intraindustry. In this regard, the USA, Switzerland, Netherlands, Canada, Denmark, Greece, Portugal, Hong Kong, Slovakia, New Zealand, and Luxemburg faced with higher IIT. A closer study shows that in most of developed countries, although experienced more changes in exporting pharmaceutical goods than importing, $\Delta \mathrm{M}$ was more than $\Delta \mathrm{X}$. Therefore, it can be concluded that developed countries are good both at imports and exports. Only Germany, Belgium, United Kingdom, Ireland, Netherlands, Austria, and Denmark had higher changes in exports than imports of pharmaceutical goods. Hence, production and exports of pharmaceutical goods in these countries showed a progressive trend.

Table 5 shows the results of measuring $\mathrm{B}^{\mathrm{A}}$ index. As it shown, changes in IIT in pharmaceutical industry correlate with positive changes in IIT in developed countries. It has to be mentioned that changes in these two indices were different for given countries, in a way that based on $\mathrm{B}^{\mathrm{A}}$ index, ranking of countries has been modified in terms of intensity and weak of MIIT. Fig. 5 shows the trend of changes in $\mathrm{B}^{\mathrm{A}}$ in the given period. Furthermore, in spite of the fact that both comparative indices of Brulhart show incremental and good level of MIIT in selected developed countries, based on $\mathrm{B}^{\mathrm{A}}$, the amount of MIIT of pharmaceutical goods faced a fundamental decrease in the end of the

Table 2: The results of mean of weighted indices of grubel-lloyd and FF for pharmaceutical goods in selected developed countries during 2000-2012

\begin{tabular}{lll}
\hline Rank in pharmaseutical trade & Country & GL index results \\
\hline 1 & EU-27 & 60.37 \\
3 & USA & 64.06 \\
5 & Switzerland & 61.58 \\
7 & France & 75.32 \\
9 & Ireland & 24.43 \\
24 & Portugal & 34.57 \\
25 & China, Hong Kong SAR & 77.82 \\
26 & Slovenia & 49.45 \\
27 & Norway & 33.6 \\
30 & Luxembourg & 28.55 \\
\hline
\end{tabular}

Due to lack of data, the weighted values of some countries, in the FF of these countries, the number is not inserted. Source: Calculations of research

Table 3: Kinds of pharmaceutical goods trade in selected developed countries during the period 2000-2012

\begin{tabular}{|c|c|c|c|c|}
\hline \multirow[t]{2}{*}{ Rank in pharmaceutical trade } & \multirow[t]{2}{*}{ Country } & \multirow[t]{2}{*}{ One-way trade } & \multicolumn{2}{|c|}{ Two-way trade } \\
\hline & & & Vertical & Horizontal \\
\hline 3 & USA & 2.6 & 95.52 & 1.88 \\
\hline 5 & Switzerland & $0 / 45$ & 96.29 & 3.26 \\
\hline 7 & France & 3.12 & 33.33 & 63.55 \\
\hline 9 & Ireland & 56.06 & 42.06 & 1.88 \\
\hline 24 & Portugal & 14.91 & 73.84 & $0 / 36$ \\
\hline 30 & Luxembourg & 6.57 & 64.29 & 29.13 \\
\hline
\end{tabular}

Source: Calculations of research 
Table 4: The results of BB index of pharmaceutical groups in selected developed countries during the period 2000-2012

\begin{tabular}{|c|c|c|c|c|c|c|c|c|c|c|c|}
\hline \multirow[t]{2}{*}{ Rank in Trad } & \multirow[t]{2}{*}{ Country } & \multicolumn{2}{|c|}{ 2012-2011 } & \multicolumn{2}{|c|}{ 2010-2009 } & \multicolumn{2}{|c|}{ 2007-2006 } & \multicolumn{2}{|c|}{ 2004-2003 } & \multicolumn{2}{|c|}{$2001-2000$} \\
\hline & & $\left|\mathrm{B}^{\mathrm{B}}\right|$ & Group & $\mathrm{B}^{\mathrm{B}}$ & Group & $\mid B^{B}$ & Group & $\left|\mathrm{B}^{\mathrm{B}}\right|$ & Group & $\left|\mathrm{B}^{\mathrm{B}}\right|$ & Group \\
\hline 1 & EU-27 & 31.03 & 29 & 27.59 & 29 & 24.14 & 29 & 25 & 28 & 10.71 & 28 \\
\hline 3 & USA & 27.59 & 29 & 31.03 & 29 & 20.69 & 29 & 35.71 & 28 & 32.14 & 28 \\
\hline 5 & Switzerland & 27.59 & 29 & 24.14 & 29 & 24.14 & 29 & 10.71 & 28 & 28.57 & 28 \\
\hline 7 & France & 20.69 & 29 & 41.38 & 29 & 48.28 & 29 & 32.14 & 28 & 28.57 & 28 \\
\hline 24 & Portugal & 14.29 & 28 & 6.9 & 29 & 13.79 & 29 & 14.29 & 28 & 17.86 & 28 \\
\hline 25 & China, Hong kong SAR & 28.57 & 28 & 46.15 & 26 & 44 & 25 & 40 & 25 & 48 & 25 \\
\hline 26 & Slovenia & 28.57 & 28 & 24.14 & 29 & 34.48 & 29 & 18.52 & 27 & 25.93 & 27 \\
\hline 27 & Norway & 6.9 & 29 & 20.69 & 29 & 25 & 28 & 18.52 & 27 & 10.71 & 28 \\
\hline 30 & Luxembourg & 7.14 & 28 & 13.79 & 29 & 14.81 & 28 & 34.62 & 26 & 10.71 & 28 \\
\hline
\end{tabular}

Table 5: The results of mean values of $B^{A}$ index for pharmaceutical sector in selected developed countries during the period 2000-2012

\begin{tabular}{lll}
\hline $\begin{array}{l}\text { Rank in } \\
\text { pharmaceutical Trade }\end{array}$ & Country & index results \\
\hline 1 & EU-27 & \\
3 & USA & 44.99 \\
5 & Switzerland & 38.55 \\
7 & France & 41.49 \\
9 & Ireland & 54.2 \\
24 & Portugal & 16.86 \\
25 & China, Hong Kong SAR & 22.63 \\
26 & Slovenia & 64.63 \\
27 & Norway & 37.31 \\
30 & Luxembourg & 29.34 \\
\hline
\end{tabular}

Source: Calculations of research

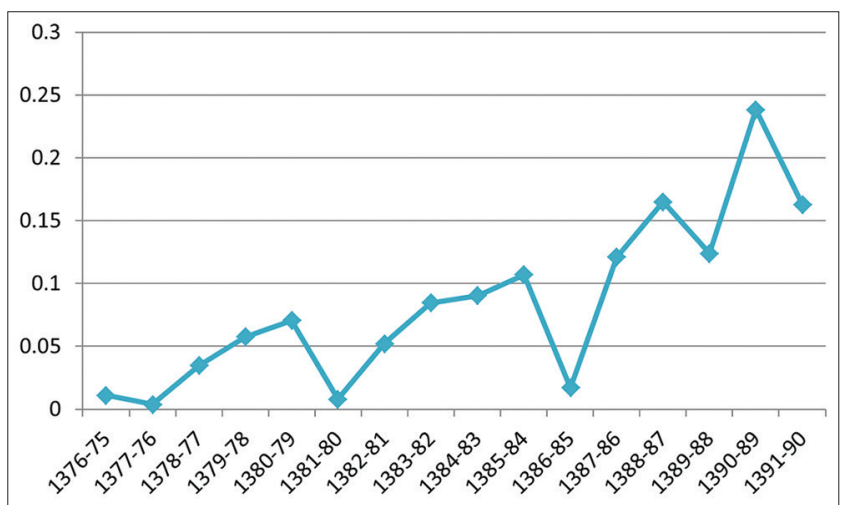

Fig. 5: Comparative indices of brulhart for all industry $\left(B^{A}\right.$ and $\left.B^{B}\right)$

given period. Moreover, based on mean values of $\mathrm{B}^{\mathrm{A}}$, during 2000-2012, Belgium, Hong Kong, Hungry, Netherlands, and France had the highest MIIT. After these countries, there were United Kingdom, Finland, EU, Italy, Canada, Switzerland, Austria, and Germany which had the highest rank in MIIT. Changes in MIIT in Hong Kong, Hungry, and Finland were substantial. As mentioned, this incremental growth suggests the high potential of these countries in gaining competitive advantages and considering operational plans and proper policies in the process of promoting production and exports of pharmaceutical goods and international competitive status. Ireland, Japan, South Korea, Portugal, Greece, Sweden, Singapore, Slovakia, Luxemburg, and Norway had the lowest volume of MIIT (lower than 30\%) over the studied period.

\section{Analysis of azhar and elliot index}

Table 6 shows the results obtained from $\mathrm{AE}$ index concerning pharmaceutical goods of selected developed countries. It is noteworthy to mention that, based on theoretical foundations, $\mathrm{B}^{\mathrm{B}}$ is a subset of $\mathrm{AE}$ index. In fact, the results of $\mathrm{AE}$ index are complementary to Brulhart comparative index. As it can be seen in Table 6, MIIT of pharmaceutical goods in all developed countries is in a high level. However, closer study shows the presence of a variable trend in MIIT in these countries. However, it can be generally mentioned that changes in IIT of all developed countries were in good status and incremental. Based on the results of AE index, IIT in USA, Switzerland, Ireland, Canada, Netherlands, Denmark, Singapore, Greece, Portugal, Hong Kong, Slovakia, New Zealand, and Luxemburg showed an increase compared to the beginning of the study. Furthermore, countries like Germany, Belgium, United Kingdom, France, and EU had higher MIIT in most of the times. Finland, Portugal, Norway, and Luxemburg were of lower MIIT during this period.

Moreover, closer study of the results showed destruction in the commercial balance of pharmaceutical sector in most of developing countries. Among these, Germany, Belgium, United Kingdom, Ireland, Netherlands, Austria, Denmark, and EU showed an improved trade balance. It should be noted that most of these countries, in spite of experiencing destructed balance, showed an incremental growth in pharmaceutical goods trade.

In general, it can be stated that the amount of MIIT in pharmaceutical industry in developed countries is in rather high levels, but its trend is not stable. In other words, changes in foreign trade in most countries move toward IIT, but fluctuations could be attributed to different issues including specific policies of every country in terms of health and chemical medicines, lifestyles, treatments, and major economic and financial crises around the world. All these issues affect countries, even those with more organized and sustainable plans and policies.

\section{DISCUSSION}

In this section to better understand the subject and comparison with other similar studies are mentioned a summary of theoretical and empirical literature: A variety of theories have been proposed regarding competitiveness. International trade theories can be divided into traditional and new ones. Traditionally, the aim of competition is dominance over market, development, and maximizing profits. However, in new theories of trade, the purpose is just customer satisfaction and improving quality of life [13].

It can be said that research on trade expansion and considering its effects on humans originate from thoughts of mercantilism school in the $18^{\text {th }}$ century. They emphasized on positive trade balance in which the volume of exports should be more than imports. Adam Smith (1871) introduced absolute advantage theory. This suggests that every country, through free trade, can gain the skills of production and exporting specific goods and also importing required goods [14]. In 1817, David Ricardo introduced comparative advantage. This theory played a vital role in constructing new ideas about trade. Based on this study, differences in productivity lead to trade between countries [15]. The problem of Ricardo's theory was the restricted expenditure for manufacturing. Haberlar (1936) defined comparative advantage theory 
Table 6: The results of AE index for pharmaceutical goods in selected developed countries during 2000-2012

\begin{tabular}{lllllll}
\hline \multirow{2}{*}{ Rank in pharmaceutical Trade } & Country & \multicolumn{4}{l}{ MIIT percent of each country in each period (AE) } \\
\cline { 3 - 6 } & & $\mathbf{2 0 0 1 - 2 0 0 0}$ & $\mathbf{2 0 0 4 - 2 0 0 3}$ & $\mathbf{2 0 0 7 - 2 0 0 6}$ & $\mathbf{2 0 1 0 - 2 0 0 9}$ & $\mathbf{2 0 1 2 - 2 0 1 1}$ \\
\hline 1 & EU-27 & 58.62 & 65.52 & 65.52 & 57.14 & 50 \\
3 & USA & 48.28 & 62.07 & 72.41 & 75 & 53.57 \\
5 & Switzerland & 48.28 & 60.71 & 55.17 & 42.86 & 57.14 \\
7 & France & 62.07 & 65.52 & 72.41 & 68.86 & 50 \\
9 & Ireland & 51.72 & 48.28 & 55.17 & 57.14 & 60.71 \\
24 & Portugal & 46.43 & 34.48 & 51.72 & 42.86 & 53.57 \\
25 & China, Hong Kong SAR & 57.14 & 62.23 & 57.69 & 52 & 64 \\
26 & Slovenia & 60.71 & 72.41 & 72.41 & 48.15 & 51.85 \\
27 & Norway & 58.62 & 55.17 & 46.43 & 48.15 & 42.86 \\
30 & Luxembourg & 35.71 & 51.72 & 42.86 & 46.15 & 42.43 \\
\hline
\end{tabular}

Source: Calculations of research

on the basis of opportunity cost theory. In this regard, countries with lower opportunity cost in the process of manufacturing a good would have comparative advantage regarding that good. Another theory in this part is the theory of Heckscher-Ohlin, based on which differences in frequency of production factors would contribute to balance in trade. This theory was one of the most influential theories in international trade. It was introduced by Eli Heckscher (1919) and Bertil Ohlin (1933), who described IIT streams among countries based on differences in the intensity and inventory of production factors

In general, it can be stated that competitiveness based on traditional theories of international trade emphasizes on the ratio of production factors and is focused on unreal principles, complete structure of competitive market, goods homogeneity, and lack of economies of scale. These unreal theories, along with changes in the nature of global trade, led to adjustment of these theories and development of new trade theories.

It is a long time that static comparative advantages theory has been replaced by the dynamic relative advantages theory. Comparative advantages of a country are not static or dynamic, but comparative advantage is a dynamic concept which is created through different time periods and is always in the process of evolution. Competitive advantage can be obtained through evolution of life cycle of product, changes in enjoyment of conditions, and achieving progressive efficiency. Based on dynamic comparative advantages theory, every country is capable of creating advantages using modern technology [16]. Therefore, competitiveness, in new theories of trade, modern factors of production including knowledge, technology, human resources, consumers' interests, marketing, innovation, and political, social and institutional issues [17]. Furthermore, in new theories, facts such as product differentiation and progressive output have been added to the list of determinants of international trade patterns. Accordingly, changing the level of competition, which seemed to be impossible in conventional models, has become possible in new models [18]. In this way, IIT is of great importance which will be dealt with in following section.

The phenomenon of IIT, which accounts for the lion's share of global trade, has come into the terminology of international trade from three decades ago. This phenomenon, which is not explainable based on common theories of international trade, has been defined and predicted by IIT models. Regarding inability of traditional theories in defining this concept, substantial IIT can possess meaningful political effects. By studying IIT in industry of a given country, the industrial structure of the economy of that country is actually evaluated. In this regard, the first studies about IIT were done by Balassa (1965) and Grubel and Lloyd in 1975.

In fact, the theory of IIT has been derived from theory of Heckscher-Ohlin. This theory has put aside some notions of Heckscher-Ohlin theory to be recognized as part of modern trade theories. Then, from the late 1970s, new theories were introduced by Krugman (1980, 1979, and
1981), Lancaster (1980), and Helpman (1981) whose purpose was to explain IIT in industrialized developed countries. Other economists like Brander (1981) and Brander and Spencer (1985) developed this theory based on progressive output compared to incomplete scale and competition [19].

Till now, no domestic studies have been conducted on competitiveness of pharmaceutical industry based on comparative and IIT indices. Foreign studies also have considered pharmaceutical industry as a part of the whole industries of a specific country. Following is a brief summary of some important studies in this field.

Pradhan (2006) used data of the Committee of Pharmaceutical R and D, data issued by the Pharmaceutical Production organization, and annual report of India Chemical and Petroleum Group to study the growth and competitiveness of pharmaceutical industry in India during the period 1970-2006. The results indicate that strategic policies of government were among the main factors changed the position of India from a mere importer of pharmaceutical goods to a powerful and creative producer of modern and efficient drugs [20]. Olmeda and Varela (2010) studied the factors affecting competitiveness in pharmaceutical industry in different countries using Global Competitiveness Report, Porter's Competitiveness Diamond Model, and data of UN regarding traded goods in 2001, 2004, and 2007. The results showed that among effective factors in diamond competitiveness model, internal factors such as infrastructures, productivity, innovation, and skilled workforce have the highest influence on competitiveness of pharmaceutical firms. Furthermore, factors related to government such as governmental rules, commercial barriers, and direct foreign investments were not effective in this industry [21]. Ito and Okubu (2012), using data of European Trades in the 8-digit level of the harmonized system (HS) and measuring simple and weighted indices of Grubel and Lloyd during the period 1988-2010, studied IIT in different industries, including drugs, in European countries, Eastern Europe, and China. The results indicated the existence of a long-term bilateral trade relationship between the studied countries [22]. In Iran, Kalbasi et al., using statistics of trade among countries in the 5-digit levels of SITC codes and in the 6-digit level of HS codes available in PC TAS CD, assessed the volume of IIT in Iran during 1997-2000. They also applied the Simple Grubel and Lloyd index. The results suggested that IIT contributes to a small share of all business transactions in Iran. The results also showed that the highest level of bilateral IIT between Iran and Thailand is for medical equipment. In 1994, Norway had the top rank in the area of other tools with medical usage, and in 19977, in the realm of tools with medical and veterinary usages [23]. In 2012, Golestani et al. showed that in the significance level $(\mathrm{p}<0.01)$, variables, gross domestic product (GDP) per capita, total health expenditure, and total pharmaceutical expenditures with per capita drug consumption had a statistically significant relationship. Based on the study results, the variables of GDP, total health expenditure and total pharmaceutical expenditures 99.3\% of the variance in per capita drug consumption and $99.8 \%$ change in total pharmaceutical expenditures can be explained. According to the 
results of the regression, the variable per capita health expenditures with a beta standard ( $\beta=0.759$ and $\beta=0.987)$ better than the variable of economic growth predicted the per capita drug consumption and total pharmaceutical expenditures variables [24]. Mahmoodzadeh et al. (2013) used both data of the International Trade Center and WITS website and also index of shift-share analysis during 2000-2010 to study the level of competitiveness of Iran in drugs exports. The results indicate that, among components of SSA index, the effect of response to changes in international demands is the only reason for promotion in comparative advantage [25]. Nasabian et al. used the data related to the period 1995-2008 and calculation of RSCA index to study comparative advantage of exporting pharmaceutical plants in Iran and eleven other main exporting countries. The findings showed that Syria, Iran, India, Turkey, Singapore, Egypt, Morocco, Bulgaria, and Vietnam possess comparative advantage, Canada and Germany lack such advantage, and China has exported comparative advantage just in some years [26]. Shabaninejad et al. used a self-designed questionnaire and sent to 65 managers at Tamin Pharmaceutical Investment Company, to assess managers' perspective about the internal and external key factors affecting the development of pharmaceutical industry. The findings showed that most managers believed generic scheme reflect negatively on the development of the pharmaceutical industry and that external factors have a great impact on its improvement. They believe that branded generic transition along with supporting regulations, investment in Research and

Development, and joint venture with foreign companies will improve the pharmaceutical industry [27]. Alamelu et al. conducted the study to know the comforts and confronts faced by pharma companies in India. It is of case study approach and presented the Indian pharmaceutical export advantages, the Government initiatives toward the export market, problems, the recent US trademark legislation issues, and the opportunities in a nutshell. The findings showed that keeping the high credibility of serving quality products in the complex market; India has gained a strong reputation among the global place [28].

\section{CONCLUSIONS}

Considering traditional and new indices of competitiveness in selected developed countries, it can be stated that the obtained results are indicative of high competitiveness of most countries. Moreover, the study findings reveal that countries with higher levels of international medicine trade are of more competitiveness, based on comparative advantage and IIT. It became clear that some countries like Ireland, Slovenia, and Greece rely on comparative advantage for competition, and other countries like Belgium, USA, and Netherlands reach a high position in the International Pharmaceutical Industry through creating competitive advantage and proper usage of goods. Some countries like Germany, Switzerland, United Kingdom, France, and EU applied both comparative and competitive advantages. Calculation of dynamic indices of IIT suggests partial growth of developed countries in the given period. Hong Kong and Hungry, although having lower levels of medicine trade, faced substantial growth. This shows their success in changing the structure of pharmaceutical sector from extra-industry to intra-industry and gaining competitive advantages in selling pharmaceutical goods.

In this regard, it is recommended that, for increase in international competitiveness in pharmaceutical industry, selected developed countries pay attention to both comparative and competitive advantages. Furthermore, due to considerable effects of IIT on the promotion of competitiveness of pharmaceutical industry in selected countries, it is recommended that they permanently develop IIT in the pharmaceutical sector.

\section{ACKNOWLEDGMENTS}

The authors are thankful of the Tabriz University of Medical Sciences and the Faculty of Economics and Administration Sciences of the University of Mazandaran.

\section{AUTHORS CONTRIBUTIONS}

Saeed rasekhi was involved in the supervision and data analysis. Seyede zeinab mousavi was involved in data collection and preparing the data for analysis and research methodology. Ali Imani and Mina Golestani were involved in study design, managing the data collection and analysis, and drafting of the manuscript.

\section{FUNDING/SUPPORT}

This study is part of a MA thesis of seyede Zeinab Mousavi that supported by the University of Mazandaran.

\section{CONFLICTS OF INTERESTS}

There are no conflicts of interests in this study.

\section{REFERENCES}

1. Imani A, Janati A, Moghimi M, Golestani M, Doshmangir L. Identification of indicators for evaluating the financial and economic performance of the pharmacy: A systematic review. Pharm Sci 2015;21:111-24.

2. Salari A, Dezh pasand F. Comparative advantage in petroleum of Iran. Q Econ Trade 2007:9:84-111

3. Mostafavi SH, Takshi N. To define the effect of absolute and comparative advantage of export on development of economy. Meysagh Iran Mag 2008;32:66-72.

4. Rasekhi S. IIT between Iran and Main Trading Partners. $3^{\text {rd }}$ ed. Tehran; Commercial Research and Study Center: 2013.

5. International Federation of Pharmaceutical Manufacturers and Associations [IFPMA]. The Pharmaceutical Industry and Global Health. Geneva: International Federation of Pharmaceutical Manufacturers and Associations; 2012.

6. Esfandiari KH, Yousefi P. Threats and Opportunities for Drugs Economy. Annual Iranian Conferences of Pharmaceutical and Treatment Economics. Tehran; 2011. p 1-19. Available from: http:// www.ipte90.cnf.ir/files site/paperlist/r 12 120416074804.pdf.

7. Vollrath TL. Weltwirtschaftliches Arch 1991;130:265-79.

8. Utkulu U, Seymen D. Revealed Comparative Advantage and Competitiveness: Evidence for Turkey visà-vis the EU/15. To be presented at the European trade study Group $6^{\text {th }}$ Annual Conference, Nottingham; 2004, 2004. p. 1-26.

9. Brasili A, Epifani P, Helg R. On the dynamics of trade pattern. Economist 2000;148:233-57.

10. Rasekhi S. Measuring IIT: A case study of factory based industries of Iran. J Econ Res 2007;81:61-84.

11. Brülhart M. Marginal Intra-Industry Trade: Towards a measure of nondisroptive trade expantion. In: Lioyd PJ, Lee HH, editors. Frontiers of Research on Intra Industry Trade. London: Palgrave; 2002. p. 1-26.

12. Tahmasebi N, Zadeh AK, Imani A, Golestani M. Evaluation of factors affecting sales of prescription medicines by econometric methods in Iran. Pharm Sci 2013;19:101-7.

13. Khanduzi E. To study the Power of Iran`s Economy in Globalization. MA Thesis. Tehran: Emam Sadegh University; 2005.

14. Appelyard DR, Alfred JF. International Economy: Trade Theory and Policy. USA: Library of Congress; 1995.

15. Davis DR. Intra-industry trade a hecksher-ohlin-ricardo approach. J Int Econ 1995;39:207-26.

16. Jafari Samimi A, Naghavi S. To study comparative advantage of value added of economic sectors in Khorasan based on third development plan. Danesh Tose'e Q 2008;23:1-24.

17. Chaharbaghi K, Lynch R. Sustainable competitive advantage: Towards a dynamic resource-based strategy. Manage Decis 1999;37:45-50.

18. Neary PJ. Competitive versus Comparative Advantage Lectures in the Department of Economics. Working Paper; 2002. p. 1-24.

19. Veermani CH. Liberalisation, Industry-Specific Factors and IntreIndustry Trade in Indi. Vol. 97. Working Paper; 2003. p. 32-47.

20. Pradhan JP. Global competitiveness of indian pharmaceutical industry: Trends and strategies. Munich Per Repec Arch 2006;12340:35-69.

21. Olmeda G, Varela J. Determinants of international competitiveness in the pharmaceutical industry. Esic Market Econ Bus J 2012;2:372-82.

22. Ito T, Okubo T. New Aspects of Intra-Industry Trade in Euro Countries. Inst Dev Econ 2012;361:20-40

23. Kalbasi H, Raeesi Ardali GH, Raeesi M. Estimates of intra industry trade, Iran. J Econ Res 2004;20:55-79. 
24. Golestani M, Rasekh HR, Imani A. The relationship between pharmaceutical expenditures, health care expenditures and gross domestic product in Iran: 1999-2008. Pharm Sci 2012;18:9-18.

25. Mahmood Zadeh M, Karimi M, Hasan Pour Y. Analysis of Iran`s power in medicine exports. Sci Res Mag Econ Policy 2012;7:57-78.

26. Nasabian SH, Gholam Hosseini T, Jebel Ameli F. To compare the comparative advantage of exporting herbal medicines with other exporting countries. Q Econ Model 2013;4:1-18

27. Ebrahim E, Shabaninejad H, Madani H, Amineh ZA. A framework for evaluation of pharmaceutical industry development in developing countries: Evidence from Iran. Asian J Pharm Clin Res 2016;9:50-4.

28. Alamelu R, Amudha R, Shakila Motha LC, Nalini R. Pharma export: Comforts and confronts in India. Asian J Pharm Clin Res 2016;9:24-6. 